\title{
A CALL FOR MANDATORY PLANETARY HEALTH EDUCATION IN PUBLIC HEALTH AND HEALTH SERVICES RESEARCH PROGRAMS
}

\author{
Victoria Haldane $^{1}$, Anna Cooper Reed ${ }^{1}$, Danielle Toccalino ${ }^{1}$, Yina Shan ${ }^{1}$, Isha Berry ${ }^{1}$, Colin Sue-Chue-Lam ${ }^{1}$ \\ ${ }^{1}$ Dalla Lana School of Public Health, University of Toronto, Toronto, Canada \\ Corresponding author: Victoria Haldane, v.haldane@mail.utoronto.ca
}

\begin{abstract}
The effects of global climate and environmental change endanger health, health systems, and public health infrastructure. As future public health and health services professionals, researchers, and clinicians, we will be tasked with protecting and promoting the health of communities in the face of these realities. However, there is limited integration of the environment-health nexus into the curricula of public health and health services research programs. Planetary health, an integrative paradigm linking the complex dynamics between the health of people to the natural systems on which we depend, offers an inroad to equipping emerging health system leaders with the skills and knowledge to protect people and the planet. We call on our institutions to follow other health disciplines, such as medicine, and embed planetary health and environmentally sustainable healthcare practices into core educational offerings.
\end{abstract}

Keywords: Planetary health; Environmental health; Public health; Health services research; Health education; Curriculum

In the face of climate and environmental change, planetary health has emerged as an integrative paradigm that both links and works to better understand the complex dynamics between the health of people and the natural systems on which we depend. ${ }^{1,2}$ Led by the world's youth, the global wave of climate strikes in 2019 demonstrated that there is wide recognition that human health is impacted by social and ecological determinants, including climate and environmental change such as chemical and plastic pollution, ocean acidification, land degradation, and biodiversity loss. ${ }^{1}$ Given these threats to human health and well-being, the ecological determinants of health have appropriately been named one of the top five strategic priorities at the Dalla Lana School of Public Health (DLSPH), and Sustainability is one of the DLSPH's core values. Yet, gaps remain in the educational opportunities currently available at DLSPH that must be addressed to better align its intentions with its actions and to equip future leaders in planetary health education and research.
Promisingly, the Public Health Sciences department at DLSPH has three courses that explicitly address concepts in planetary health, one of which - Directed Reading: Planetary Health - has been used as an exemplar for planetary health education by the Planetary Health Alliance. ${ }^{3}$ However, none of these courses are mandatory and, as a result, are not regularly offered. Though specializations are available in Occupational and Environmental Health as well as Environment and Health (through the School of the Environment), neither of these offerings specifically relate to planetary health or the ecological determinants of health. At the Institute of Health Policy, Management and Evaluation (IHPME), an institute affiliated with DLSPH, there have historically been no courses addressing the environment-health nexus, although action towards the implementation of such courses is beginning.

DLSPH is not alone in its limited incorporation of planetary health in its course offerings. Public health and health services research education in Canada offers little planetary health training, with no mandatory competencies on the ecological 
determinants of health or the environmental impacts of healthcare. ${ }^{4,5}$ Only $52 \%$ of Canada's public health schools and faculties offer at least one course related to the ecological determinants of health, and only 3\% of Canada's public health graduate programs require the completion of a course related to the ecological determinants of health. ${ }^{4}$

Other health disciplines, most notably medicine, have recognized the urgent need to equip their students with planetary health knowledge in order to safeguard the health of patients and the planet. Calls for integrating planetary health into clinical education have highlighted how such an approach "allows students to develop professional attitudes and skills to cope with complex problems in interprofessional collaborations." 5 The Canadian Federation of Medical Students' Health and Environment Adaptive Response Taskforce (HEART) has developed core planetary health curricular competencies for medical learners and is leading efforts to integrate planetary health into the curricula of all Canadian medical schools. ${ }^{7}$ Their work draws upon resources from international and national networks, including the Centre for Sustainable Healthcare (CSH) and the Canadian Association of Physicians for the Environment (CAPE). ${ }^{8,9}$ Similar efforts can be made by DLSPH and public health schools across Canada by drawing upon robust resources from the Canadian Public Health Association's Ecological Determinants Group on Education (EDGE) ${ }^{10}$ the Community of Practice in Ecosystem Approaches to Health (CoPEH) Canada, ${ }^{11}$ and the Planetary Health Alliance. ${ }^{3}$ More foundational work is needed to establish such competencies for health services and policy research trainees at IHPME and beyond. Despite a recent effort to develop enriched core competencies for health services and policy research doctoral students, planetary health is notably lacking. ${ }^{11}$

The push to integrate planetary health into graduate health education, training, and professional development is timely and urgent. In Canada, we are already experiencing the health effects of climate and environmental change. For example, illnesses from heat, air pollution, water contamination, and vector-borne and zoonotic diseases are occurring in our communities with increasing frequency and with disproportionate impact on rural, remote, and marginalized communities. ${ }^{12,13}$ The COVID-19 pandemic, a disease with zoonotic origins, is the latest example exposing vulnerabilities at the human-animal-environment interface and its profound and inequitable impact on human health and well-being. ${ }^{14}$ However, the provision of health care is itself a carbon intensive act contributing to global emissions. If the global health sector were a country, it would be the fifth largest emitter on the planet. ${ }^{15}$ The effects of global climate and environmental change not only endanger our health, but also require our health systems and public health infrastructure and workforce to meet the demands of multiplying crises. ${ }^{16}$ Yet, there is little mention of these realities in public health or health services research curricula offered at DLSPH.

It is clear that in our future roles as public health and health services professionals, researchers, and clinicians, we will be tasked with protecting and promoting the health of communities. To do this effectively, we must be able to understand the impacts of environmental change as an underlying determinant of health as well as its human rights and equity implications. Further, we must be able to learn from and co-develop solutions with community partners. Leading institutions, such as DLSPH, must rapidly adapt to ensure their graduates are equipped with the tools necessary to approach problems of planetary health, and collaborate with community partners to deliver innovative, equitable, and sustainable solutions to ongoing and emerging health threats.

DLSPH has set out a bold vision for a public health and health services research education that must be followed by bold action. The frameworks, content, and interest in planetary health training exist at DLSPH already, authors on this commentary have convened with IHPME faculty to co-design a Sustainable Health Systems reading course. As well, the Fall 2020 Intro to Public Health Sciences course, which is mandatory for all incoming graduate students, included a lecture on climate 
change and health. However, there is more to be done. As students of IHPME and DLSPH, we call on our institutions to convene and ensure bold action and further concrete steps are taken to prepare future healthcare leaders with the knowledge and tools to protect both people and the planet. This means establishing clear pathways for students to integrate planetary health and environmental sustainability into their thesis work and ensuring all students are exposed to and have the opportunity to engage the planetary health paradigm regardless of thesis topic. Further commitment must be made to evaluate how best to incorporate planetary health into curricula, whether by integrating it into the existing course offerings, developing new courses, or some combination. Curricular development work should be funded to achieve these goals. We recognize that adding new educational content is a demanding process, and that DLSPH faculty face constraints of time and material resources. Nonetheless, we firmly believe that our institutions should fully step into their unique role in safeguarding planetary health. To do so is our collective task, and we must each do our part.

\section{Competing interests}

None declared

\section{References}

1. Whitmee S, Haines A, Beyrer C, et al. Safeguarding human health in the Anthropocene epoch: Report of the Rockefeller Foundation-Lancet Commission on planetary health. The Lancet. 2015;386(10007):1973-2028.

2. Pongsiri MJ, Bickersteth S, Colón C, et al. Planetary health: from concept to decisive action. The Lancet Planetary Health. 2019;3(10):e402-4.

3. Planetary Health Alliance. Build Your Course [Internet]. [cited 2020 Jun 3]; Available from: https://www.planetaryhealthalliance.org/build-yourcourse

4. Yassi A, Lockhart K, Gray P, Hancock T. Is public health training in Canada meeting current needs? Defrosting the paradigm freeze to respond to the post-truth era. Critical Public Health 2019;29(1):40-7. 5. Walpole SC, Barna S, Richardson J, Rother HA. Sustainable healthcare education: integrating planetary health into clinical education. The Lancet Planetary Health. 2019;3(1):e6-7.

6. Hackett F, Got T, Kitching GT, MacQueen K, Cohen A. Training Canadian doctors for the health challenges of climate change. The Lancet Planetary Health. 2020;4(1):e2-3.

7. Centre for Sustainable Healthcare. Centre for Sustainable Healthcare [Internet]. [cited 2019 Dec 5]; Available from: https://sustainablehealthcare.org.uk/

8. Canadian Association of Physicians for the Environment [Internet]. CAPE. [cited 2020 Nov 30]; Available from: https://cape.ca/

9. Parkes MW, Poland B, Allison S, et al. Preparing for the future of public health: ecological determinants of health and the call for an eco-social approach to public health education. Canadian Journal of Public Health. 2020;111(1):60-4

10. Community of Practice in Ecosystem Approaches to Health-Canada. About Emerging Scholars and Practitioners [Internet]. [cited 2020 Jun 3]; Available from: http://www.copeh-canada.org/en/emerging-scholars/about-esap.html

11. Canadian Institutes of Health Research. Canadian Health Services and Policy Research Alliance: Training Modernization in Health Services and Policy Research [Internet]. 2016 [cited 2020 Dec 19]; Available from: https://cihr-irsc.gc.ca/e/49883.html

12. Howard C, Buse C, Rose C, MacNeil A, Parkes M. The Lancet Countdown on Health and Climate Change Policy Brief for Canada [Internet]. Canadian Coalition for Global Health Research. [cited 2019 Dec 5]; Available from: https://www.ccghr.ca/wp-content/uploads/2018/10/2019-Policy-brief-for-Canada compressed.pdf

13. Watts N, Amann M, Arnell N, et al. The 2019 report of The Lancet Countdown on health and climate change: ensuring that the health of a child born today is not defined by a changing climate. The Lancet. 2019;394(10211):1836-78.

14. Lu R, Zhao X, Li J, et al. Genomic characterisation and epidemiology of 2019 novel coronavirus: implications for virus origins and receptor binding. The Lancet. 2020;395(10224):565-74

15. Karliner J, Slotterback S, Boyd R, Ashby B, Steele K. Health care's climate footprint: the health sector contribution and opportunities for action. European Journal of Public Health. 2019;30(S5): ckaa165.843, https://doi.org/10.1093/eurpub/ckaa165.843

16. Kruk ME, Myers M, Varpilah ST, Dahn BT. What is a resilient health system? Lessons from Ebola. The Lancet. 2015;385(9980):1910-2. 